\begin{tabular}{l|l|l}
\hline \hline Vol. 29(4):311-316 & Ocean and Polar Research & December 2007 \\
\hline \hline
\end{tabular}

\title{
Note
}

\author{
자동기록식 수중청음기를 이용한 저주파 해양잡음의 측정 \\ 김봉채 ${ }^{*}$ 김병남 · 조홍상 \\ 한국해양연구원 해양환경연구본부 \\ (425-600) 경기도 안산시 안산우체국 사서함 29호
}

\section{Measurement of Low-Frequency Ocean Noise by a Self-Recording Hydrophone}

\author{
Bong-Chae Kim*, Byoung-Nam Kim, and Hong Sang Cho \\ Marine Environment Research Department, KORDI \\ Ansan P.O. Box 29, Seoul 425-600, Korea
}

\begin{abstract}
Ocean noise may be used for monitoring wind speed and rainfall rate on the sea surface, as well as for tracking whales' migration routes. In particular, low-frequency ocean noise has recently been of concern with relation to the behavior of marine mammals. Low-frequency ocean noise has been increasing over the past few decades due to increase of ship traffic and offshore oil industry activities. Mechanical noise such as flow noise and cable strumming noise may be induced if low-frequency ocean noise is measured by cabled traditional hydrophone in high current areas. To successfully measure low-frequency ocean noise in a shallow water environment with strong current, we developed a self-recording hydrophone. This paper describes the main configurations of the self-recording hydrophone and presents some results on measured data.
\end{abstract}

Key words : low-frequency ocean noise, self-recording hydrophone, current velocity, wind speed

\section{1. 서 론}

해양잡음은 해양의 수중음향 특성을 나타내는 주요 현 상중의 하나로서 수중음파를 신호로 다룰 때 신호 대 잡 음비를 산출하는 데 필요하다. 그리고 해양잡음은 소나와 같은 수중음향 장비의 탐지성능을 예측할 때 소나방정식 의 입력변수로 사용되고 있다(Urick 1983). 또한 해양잡음 은 해표면상의 풍속 및 강우량 등의 해양환경을 원격적으 로 측정하는 데 사용될 뿐만 아니라 대형 고래류의 자원 량 및 이동경로를 추정하기 위한 기초자료로도 활용되고 있다(Lemon 1984; Nystuen 1986; Heimlich et al. 2005). 해양잡음에 관한 연구는 제2차 세계대전 이후 Knudsen et al.(1948) 및 Wenz(1962) 등에 의해 체계적으로 실시되

\footnotetext{
*Corresponding author. E-mail : bckim@kordi.re.kr
}

었고, 그 후 여러 연구자들에 의해 매우 활발히 추진되어 왔다(Kerman 1988; Kerman 1993; Buckingham and Potter 1995). 최근 Andrew et al.(2002) 및 McDonald et al. (2006)는 저주파 해양잡음 레벨이 선박통행량, 해저유전 개발 및 연안 토목공사 등의 증가로 인해 서서히 증가하 고 있음을 보고하였다. 특히 대형 고래류 등 해산 포유류 를 보호할 목적으로 해양잡음과 고래류 행동과의 관련에 대해 관심을 갖게 되었다(National Research Council 2003). 수중청음기는 수중에서 음파를 수신하여 전기신호를 출 력하는 수중음향의 기본적인 측정장비다. 이러한 목적을 달성하기 위해 케이블로 연결된 종래의 수중청음기는 일 반적으로 수중청음기 센서, 전치 증폭기, 케이블 및 케이 블 커넥터 등으로 구성되어 있다. 특히 해양에서 사용되는 수중청음기는 해상의 가혹한 사용조건 및 고압의 정수압 등에 견딜 수 있도록 견고하게 제작되고 있다. 그러나 종 
래의 케이블로 연결된 수중청음기는 긴 케이블 때문에 취급이 매우 불편하다. 최근 이 등(2004)은 원격조절 방 식으로 선박의 방사잡음을 측정할 수 있는 부표형 수중 음향신호 측정체계를 개발하였고, 미국 NOAA의 태평양 해양환경연구소(Pacific Marine Environmental Laboratory) 의 해양음향 연구자들은 해저지진 활동 등을 모니터링하 기 위해 계류형 자율 수중청음기(Moored Autonomous Hydrophones)를 개발하였다. 그러나 이들 시스템은 규모 가 매우 클 뿐만 아니라 연구용으로 개발되었기 때문에 판매되지 않고 있는 실정이다.

케이블로 연결된 종래의 수중청음기를 사용하여 해수의 흐름이 강한 해역에서 저주파 해양잡음을 측정하는 경우 특별한 주의가 필요하다. 해류·조류에 의한 해수의 흐름 은 흐름잡음(flow noise) 및 케이블 스트러밍 잡음(cable strumming noise)을 발생시킬 수 있기 때문이다(Urick 1983). 해수의 흐름이 강한 천해에서 저주파 해양잡음을 측정하는 데 사용하기 위해 휴대용 자동기록식 수중청음 기를 개발하였다. 여기에서는 개발된 자동기록식 수중청 음기에 대하여 소개한다. 그리고 자동기록식 수중청음기 에 의한 저주파 해양잡음의 측정결과에 대하여 고찰한다.

\section{2. 해양잡음 측정}

저주파 해양잡음을 측정하는 데 사용하기 위해 광대역 자동기록식 수중청음기(Kim 2006)를 참고하여 저주파용 자동기록식 수중청음기를 새로이 개발하였다. 개발된 수 중청음기의 기본적인 구성을 블록 다이어그램으로 Fig. 1 에 나타내었다. Fig. 1에 나타낸 바와 같이 자동기록식 수 중청음기는 수중청음기 센서, 필터와 증폭기, 변환기와 제 어기를 갖춘 중앙처리장치(CPU), 메모리, 정밀시계 및 전 지로 구성되어 있다. 특히 수중청음기 센서로는 수신감도 주파수 특성을 고려하여 저주파 수신감도가 평탄한 브뤼

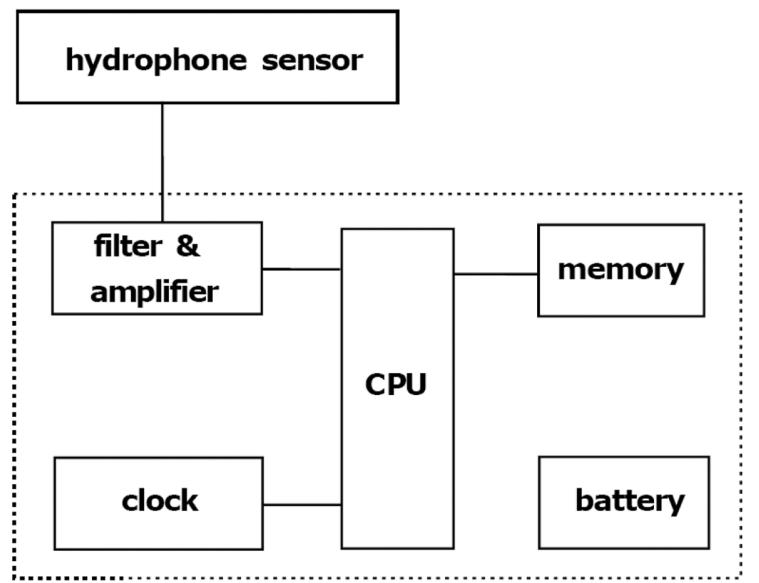

Fig. 1. Block diagram of the self-recording hydrophone.

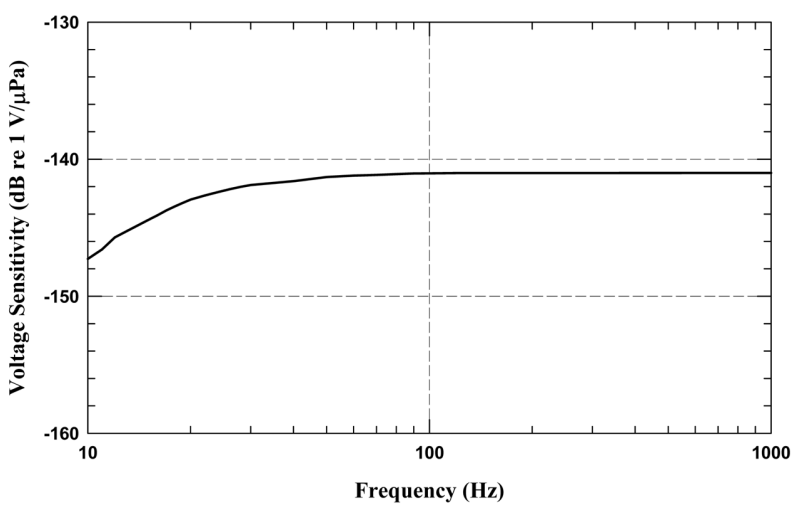

Fig. 2. Receiving voltage sensitivity of the self-recording hydrophone.

엘 앤드 케아(Bruel and Kjaer)의 모델 8103을 사용하였 다. 개발된 자동기록식 수중청음기의 경우 수중청음기 센 서에서 음향신호를 수신하여 전기신호로 변환시킨 후, 이 것을 필터와 증폭기에서 주파수 $16 \mathrm{~Hz}$ 이상의 신호만을 여과하여 적정한 레벨로 증폭시킨다. 그리고 나서 이 신호 를 CPU에서 16비트, $4096 \mathrm{~Hz}$ 로 샘플링하여 메모리에 기 록시킨다.

개발된 자동기록식 수중청음기의 수신감도 주파수 특성 을 Fig. 2에 나타내었다. 여기에서는 표준 수중청음기 수 신감도를 기준으로 비교 교정법(김 2006)을 사용하여 자 동기록식 수중청음기의 수신감도를 구하였다. 이때에는 인위적으로 실내수조의 수중에 발생시킨 충격파를 사용하 였다. 또한 자동기록식 수중청음기 전기회로의 입출력 단 자에서 인가된 입력전압에 대한 출력전압을 측정하여 실 내수조 측정결과와 동일함을 확인하였다. Fig. 2에 나타낸 자동기록식 수중청음기의 수신감도는 약 $-141.0 \mathrm{~dB}$ re $1 \mathrm{~V} / \mu \mathrm{Pa}$ 이었고, 주파수 대역 $16 \sim 1000 \mathrm{~Hz}$ 에서 $3 \mathrm{~dB}$ 이내 로 매우 평탄하였다.

수심이 약 $52 \mathrm{~m}$ 인 남해 연안의 한 정점에서 2006년 10 월중에 24 시간 동안 해양잡음을 측정하였다. 이때에는 측

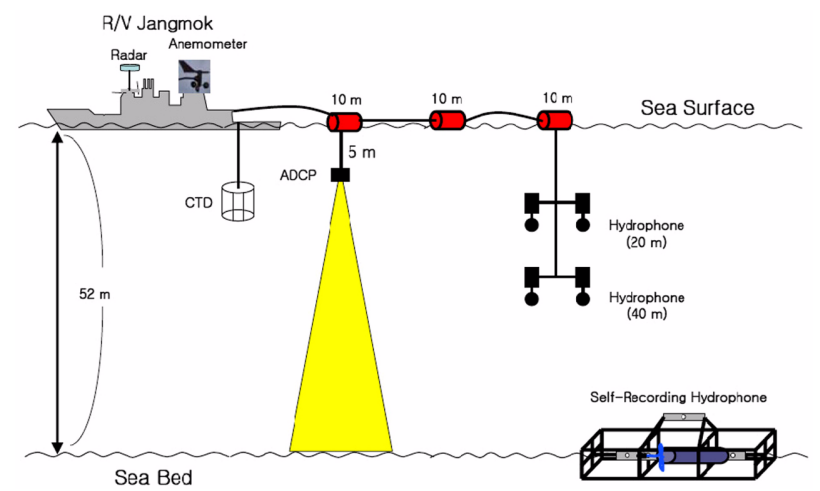

Fig. 3. Schematic view on arrangement of measuring instruments. 
정장비를 Fig. 3과 같이 설치하였다. 해상에 정지된 연구 선 「장목호」로부터 약 1마일 떨어진 곳에서 자동기록 수중청음기를 해저면에 설치하여 해양잡음을 측정하였다. 그리고 비교하기 위한 해양잡음 측정자료를 획득하기 위 해 연구선으로부터 케이블로 연결된 종래의 수중청음기를 각각 수심 $40 \mathrm{~m}$ 및 $20 \mathrm{~m}$ 에 위치시켜 해양잡음을 동시에 측정하였다. 해상에서 해양잡음을 측정하는 동안 주변환 경으로서 풍속, 유속 및 주변 항행선박을 조사하였다. 풍 속계(Weather Wizard III 7425)를 사용하여 매분 간격으 로 풍속을 측정하였고, $\mathrm{ADCP}($ Acoustic Doppler Current Profiler; RD Instruments 300)를 사용하여 매 5분 간격으 로 유속을 측정하였으며, 레이더(C80 $48 \mathrm{~nm})$ 를 사용하여 매 5 분 간격으로 주위 항행선박을 조사하였다. 조사선을 중심으로 반경 3 마일 이내에 항행하는 선박이 없는 경우 에 한해서 매 5 분 간격으로 30 초 동안씩 평균하여 $1 \mathrm{~Hz}$ 의 간격으로 $10 \sim 1000 \mathrm{~Hz}$ 의 주파수 범위에 대해 해양잡음의 스펙트럼 레벨을 구하였다. 그리고 이때에는 Fig. 2에 나 타낸 자동기록식 수중청음기 수신감도를 보상하였다.

\section{3. 결과 및 고찰}

주변환경으로서 해양잡음을 측정하는 동안 유속 및 풍 속의 시간변동을 Fig. 4에 나타내었다. 이들 그림에서 회 색으로 칠한 부분이 해양잡음 및 주변환경을 분석한 시 간대이다. 해양잡음을 측정하는 동안 유속은 조류의 영향 에 의해 $0 \sim 0.8 \mathrm{~m} / \mathrm{s}$ 의 범위내에서 시간에 따라 심하게 변 동하였다. 특히 이러한 현상은 수심 $40 \mathrm{~m}$ 및 $52 \mathrm{~m}$ 각각 의 해수층에 비해 수심 $20 \mathrm{~m}$ 의 해수층에서 더욱 현저하 였다. 해양잡음을 측정하는 동안 풍속은 $0 \sim 4 \mathrm{~m} / \mathrm{s}$ 의 범위 내에서 시간에 따라 변동하였지만, 해상상태는 대체로 양

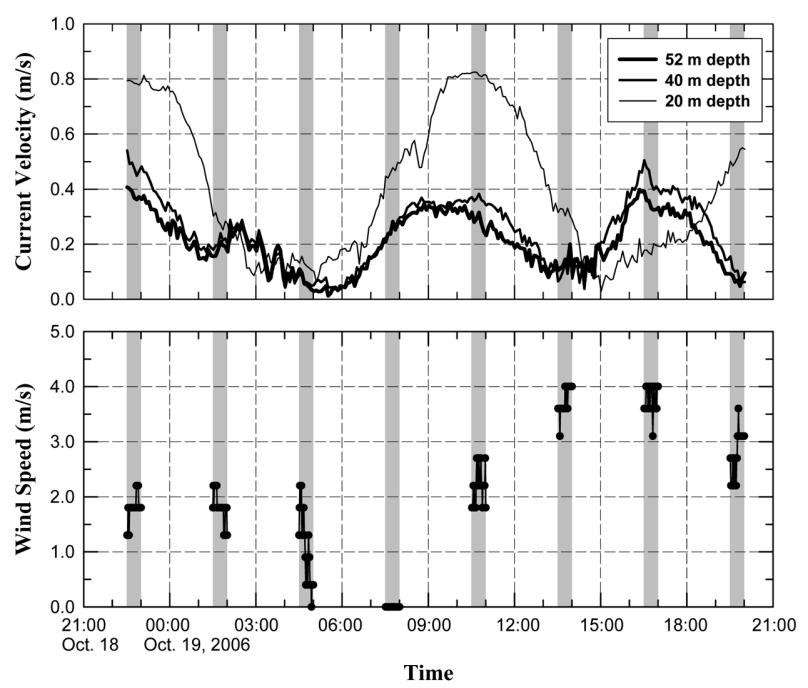

Fig. 4. Variations of current velocity and wind speed with time.

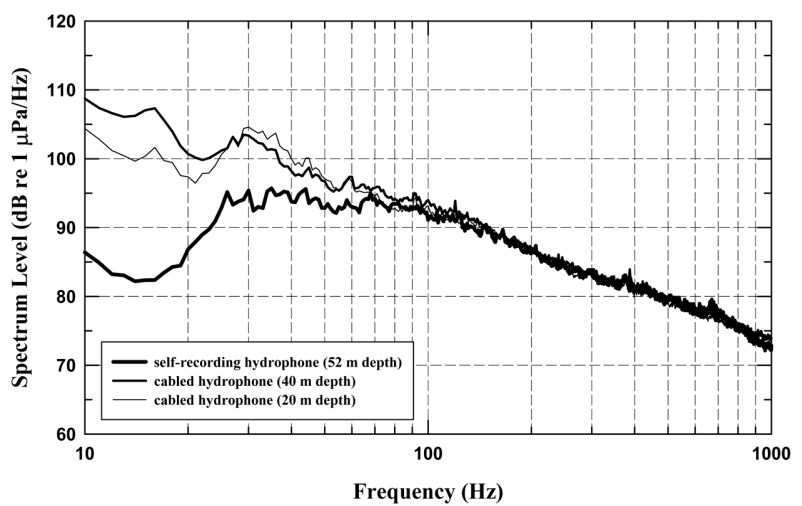

Fig. 5. Averaged ocean noise spectrum level.

호하였다.

해저면에 설치된 자동기록식 수중청음기(수심 $52 \mathrm{~m}$ )로 측정한 해양잡음 스펙트럼 레벨의 평균치를 Fig. 5 에 나타 내었다. 그리고 이 그림에는 수심 $40 \mathrm{~m}$ 및 $20 \mathrm{~m}$ 에 위치 시킨 케이블로 연결된 종래의 수중청음기로 측정한 해양 잡음 레벨의 평균치도 동시에 나타내었다. 이 측정결과는 심해에서의 측정결과(Andrew et al. 2002)에 비해 약간 높 게 나타났다. 그리고 주파수 대역 $64 \sim 1000 \mathrm{~Hz}$ 에서 자동기 록식 수중청음기로 측정한 해양잡음의 스펙트럼 레벨은 케이블로 연결된 수중청음기로 측정한 해양잡음 레벨과 거의 동일하였다. 그러나 주파수 대역 10 63 Hz에서 자동 기록식 수중청음기로 측정한 해양잡음 스펙트럼 레벨은 케이블로 연결된 수중청음기로 측정한 해양잡음 레벨보다 약 3 $25 \mathrm{~dB}$ 정도 낮게 나타났다. 특히 이러한 경향은 주 파수 대역 10 25 Hz에서 더욱 현저하였다.

자동기록식 수중청음기로 측정한 해양잡음 스펙트럼 레 벨의 평균치 및 표준편차를 Fig. 6 에 나타내었다. 여기에

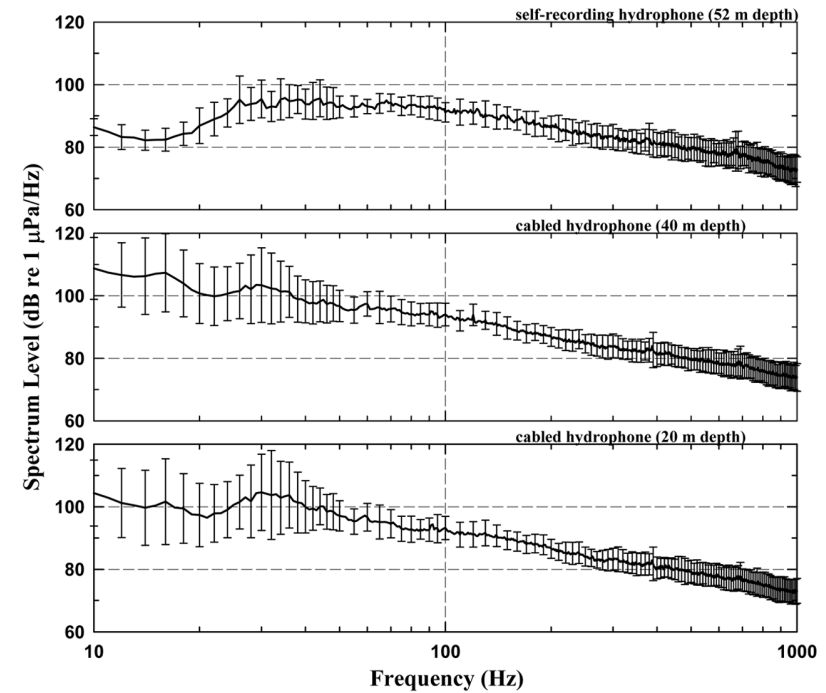

Fig. 6. Mean and standard deviation of ocean noise spectrum level. 
서는 각각의 주파수에 대한 해양잡음 레벨의 평균치를 중 심으로 표준편차를 2 배한 범위를 나타내고 있다. 그리고 이 그림에는 수심 $40 \mathrm{~m}$ 및 $20 \mathrm{~m}$ 에 위치시킨 케이블로 연 결된 종래의 수중청음기로 측정한 해양잡음 스펙트럼 레 벨의 평균치 및 표준편차도 나타내었다. 주파수 대역 60 $1000 \mathrm{~Hz}$ 에서 자동기록식 수중청음기로 측정한 해양잡음 스펙트럼 레벨의 표준편차는 케이블로 연결된 수중청음기 로 측정한 해양잡음 레벨의 표준편차와 거의 동일하였다. 그러나 주파수 대역 10 60 Hz에서 자동기록식 수중청음 기로 측정한 해양잡음 스펙트럼 레벨의 표준편차는 케이 블로 연결된 수중청음기로 측정한 해양잡음 레벨의 표준 편차보다 매우 낮게 나타났다. 그리고 자동기록식 수중청 음기의 경우 해양잡음 스펙트럼 레벨의 표준편차는 주파 수 대역 $10 \sim 20 \mathrm{~Hz}$ 및 $50 \sim 1000 \mathrm{~Hz}$ 에 비해 주파수 대역 $20 \sim 50 \mathrm{~Hz}$ 에서 약간 높게 측정되었다. 그러나 케이블로 연 결된 수중청음기의 경우 해양잡음 스펙트럼 레벨의 표준 편차는 주파수 대역 $40 ~ 1000 \mathrm{~Hz}$ 에 비해 주파수 대역 $10 \sim 40 \mathrm{~Hz}$ 에서 매우 높게 나타났다.

Fig. 4 및 Fig. 5에 나타낸 해양잡음의 측정결과에 의하 면, 특이한 현상으로서 주파수 대역 10 63 Hz에서 자동기 록식 수중청음기로 측정한 해양잡음 레벨은 케이블로 연 결된 종래의 수중청음기로 측정한 해양잡음 레벨에 비해 매우 낮게 나타났다. 이러한 원인을 조사하기 위해 특정 주파수의 해양잡음 레벨과 그때의 유속 또는 풍속 등과의 관련을 조사하였다. 여기에서는 특정 주파수로서 자동기 록식 수중청음기 및 재래식 수중청음기로 측정한 결과가 서로 매우 상이한 $20 \mathrm{~Hz}$ 와 서로 거의 차이가 없는 $100 \mathrm{~Hz}$ 를 각각 선정하였다.

먼저 유속에 대한 주파수 $20 \mathrm{~Hz}$ 및 $100 \mathrm{~Hz}$ 각각의 해양 잡음 레벨을 Fig. 7에 나타내었다. 그리고 이들 그림에는 해양잡음 레벨을 유속에 대해 선형회귀식으로 근사하였을 때의 상관계수(r)도 표시하였다. 이 결과에 의하면, 주파수 $100 \mathrm{~Hz}$ 의 경우 해양잡음 레벨은 유속과 거의 상관이 없는 것으로 나타났다. 그러나 주파수 $20 \mathrm{~Hz}$ 의 경우 자동기록 식 수중청음기로 측정한 잡음레벨은 유속과 거의 상관이 없었지만, 케이블로 연결된 수중청음기로 측정한 잡음레 벨은 유속과 다소 상관이 있는 것으로 나타났다. 즉 자동 기록식 수중청음기의 경우 해양잡음을 비교적 잘 측정하 였지만, 케이블이 부착된 재래의 수중청음기의 경우 해수 의 흐름에 의한 흐름잡음 및 케이블 스트러밍 잡음이 혼 입된 해양잡음을 측정한 것으로 생각된다.

그 다음 풍속에 대한 주파수 $20 \mathrm{~Hz}$ 및 $100 \mathrm{~Hz}$ 각각의 해양잡음 레벨을 Fig. 8에 나타내었다. 그리고 이들 그림 에는 해양잡음 레벨을 풍속에 대해 선형회귀식으로 근사 하였을 때의 상관계수(r)도 표시하였다. Fig. 8에 의하면, 풍속은 $4 \mathrm{~m} / \mathrm{s}$ 이하로서 다양한 풍속에 대한 해양잡음 레

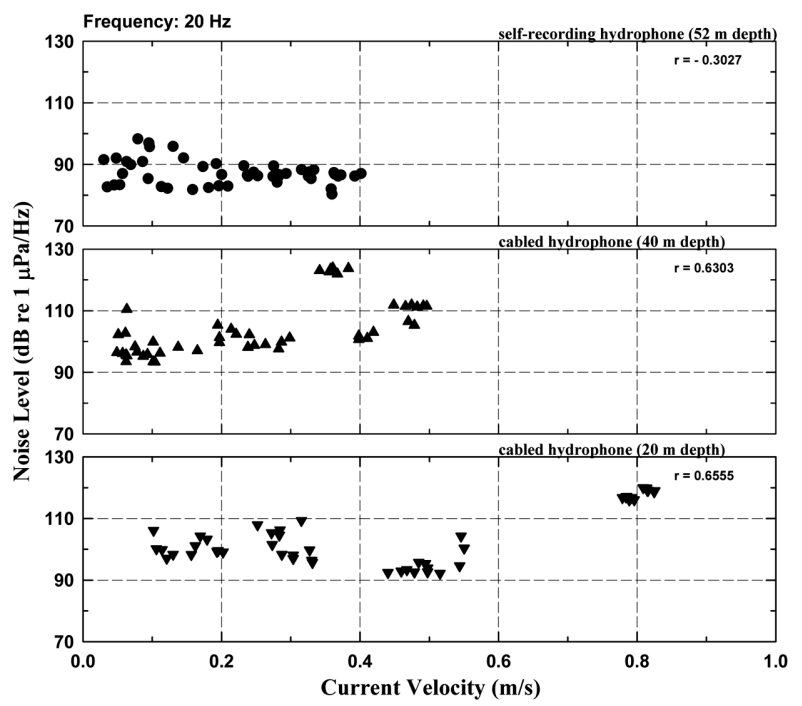

(a)

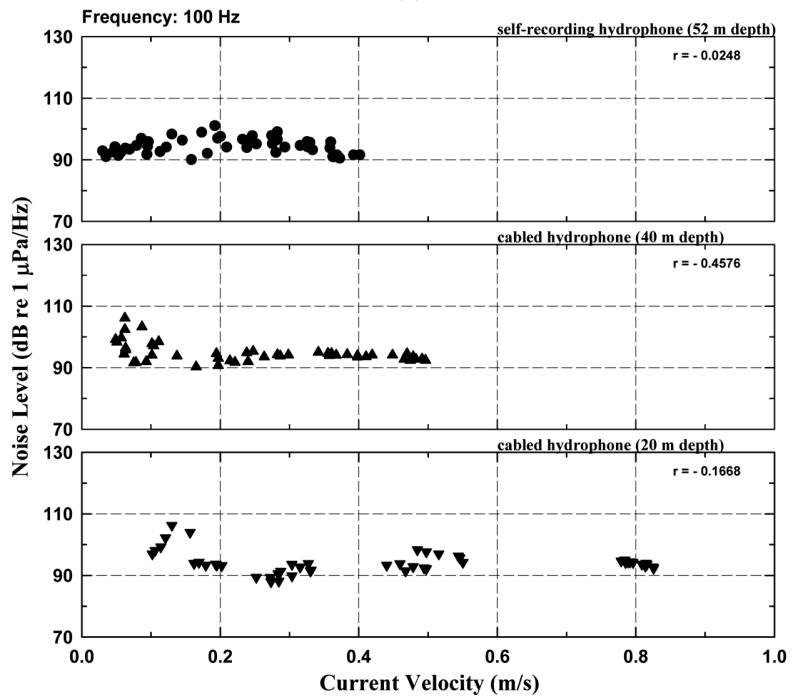

(b)

Fig. 7. Ocean noise level at selected frequencies versus current velocity.

벨의 측정결과가 부족하지만, 주파수 $20 \mathrm{~Hz}$ 및 $100 \mathrm{~Hz}$ 각 각의 해양잡음 레벨은 풍속과 거의 관련이 없는 것으로 나타났다. 일반적으로 해면상의 바람은 주파수 대역 $500 \mathrm{~Hz} 50 \mathrm{kHz}$ 의 해양잡음을 발생시키는 것으로 보고되 고 있는 데(Urick 1983), Fig. 8의 결과는 이러한 사실과 비교적 잘 일치한 것으로 생각된다.

Fig. 4 및 Fig. 5에 나타낸 바와 같이 주파수 대역 10 $63 \mathrm{~Hz}$ 에서 케이블로 연결된 종래의 수중청음기로 측정한 해양잡음 레벨은 자동기록식 수중청음기로 측정한 해양잡 음 레벨에 비해 매우 높게 나타났는데, 이것은 케이블로 연결된 수중청음기의 경우 해수의 흐름에 의해 발생된 잡 음이 해양잡음에 영향을 미쳤기 때문으로 판단된다. 따라 서 해수의 흐름이 강한 해역에서 저주파 해양잡음을 측정 


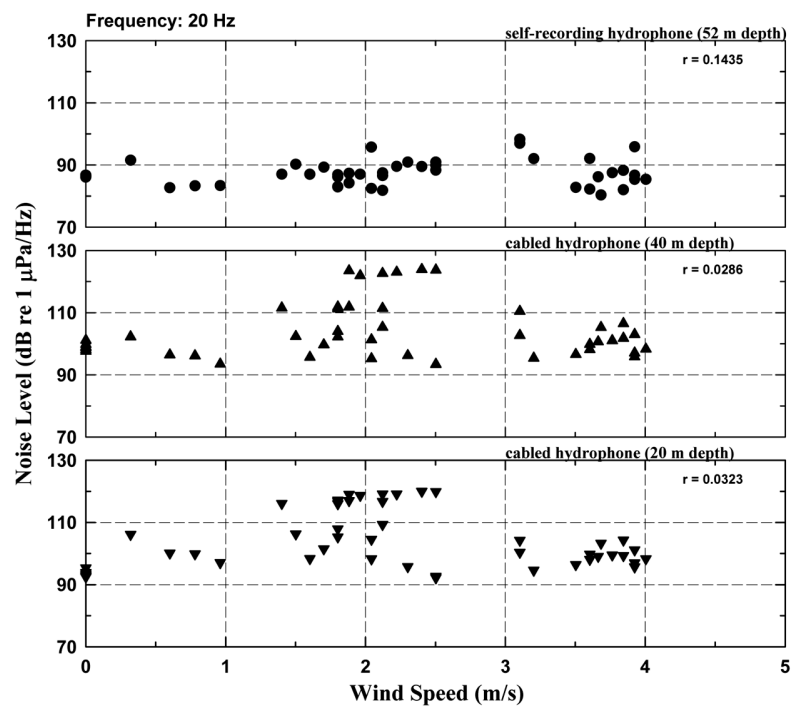

(a)

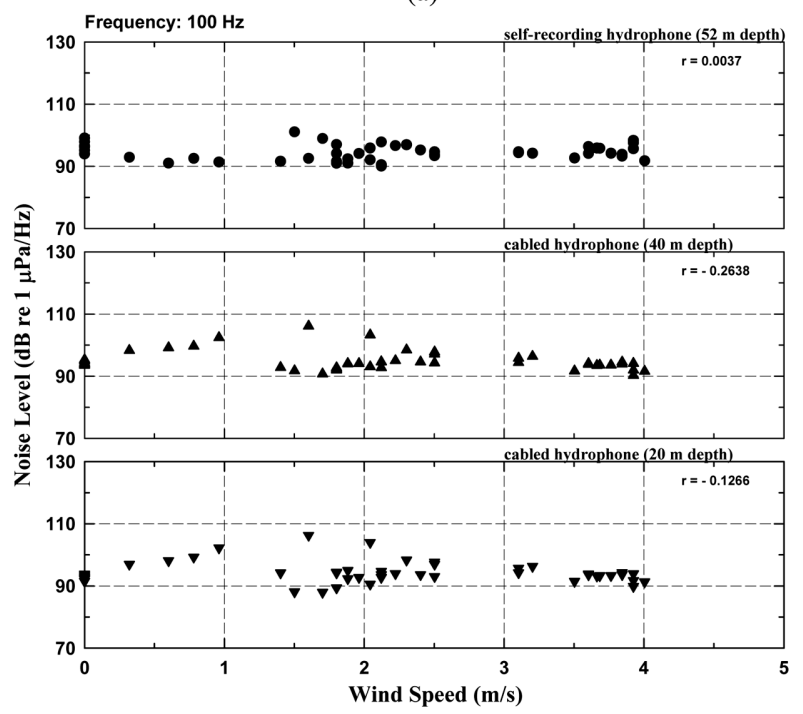

(b)

Fig. 8. Ocean noise level at selected frequencies versus wind speed.

하는 경우 케이블이 연결된 종래의 수중청음기를 사용할 때에는 흐름 잡음 및 케이블 스트러밍 잡음 등이 발생하 지 않도록 특별한 주의가 필요하다. 그리고 이 경우 자동 기록식 수중청음기가 매우 유용하게 사용될 수 있을 것으 로 생각된다.

\section{4. 결 론}

저주파 해양잡음을 측정하는 데 사용하기 위해 자동기 록식 수중청음기를 개발하였다. 남해 연안의 한 정점에서 자동기록식 수중청음기를 사용하여 저주파 해양잡음을 측 정하였다. 그리고 이때에는 비교자료를 획득하기 위해 케 이블 방식의 수중청음기를 동시에 사용하여 저주파 해양
잡음을 측정하였다. 그 결과 개발된 자동기록식 수중청음 기는 해양잡음을 측정하는 데 원활하게 작동하였으며, 양 호한 저주파 해양잡음의 측정치를 제공하였다. 특히 자동 기록식 수중청음기는 주파수 대역 $10 \sim 63 \mathrm{~Hz}$ 의 해양잡음 을 양호하게 측정한 데 비해 케이블이 연결된 수중청음기 는 해수의 흐름에 의해 발생된 흐름잡음 및 케이블 스트 러밍 잡음 등의 영향으로 해양잡음을 양호하게 측정할 수 없었다. 앞으로 자동기록식 수중청음기를 사용하여 한반 도 주변해양에서 저주파 해양잡음을 활발히 측정할 예정 이다.

\section{사 사}

본 논문을 검토해 주시고 유익한 조언을 해주신 두 분 의 심사위원께 깊이 감사드립니다.

\section{참고문헌}

김봉채. 2006. 휴대용 수중청음기 배열 시스템의 개발. 한국 음향학회지, 25, 178-183.

이필호, 허보현. 2004. 원격조절 부표형 수중음향신호 측정체 계 설계. 제 5 회 해상무 기체계 발전 세미나. 국방과학연 구소, 537-542.

Andrew, R.K., B.M. Howe, J.A. Mercer, and M.A. Dzieciuch. 2002. Ocean ambient sound: Comparing the 1960s with the 1990s for a receiver off the California coast. Acoust. Res. Lett. Online, 3, 65-70.

Buckingham, M.J. and J.R. Potter. 1995. Sea Surface Sound '94 - Proceedings of the III International Meeting on Natural Physical Processes Related to Sea Surface Sound. World Scientific, Singapore.

Heimlich, S.L., D.K. Mellinger, S.L. Nieukirk, and C.G Fox. 2005. Types, distribution, and seasonal occurrence of sounds attributed to Bryde's whales(Balaenoptera edeni) recorded in the eastern tropical Pacific, 19992001. J. Acoust. Soc. Am., 118, 1830-1837.

Kerman, B.R. 1988. Sea Surface Sound - Natural Mechanism of Surface Generated Noise in the Ocean. Kluwer, Dordrecht.

Kerman, B.R. 1993. Natural Physical Sources of Underwater Sound - Sea Surface Sound(2). Kluwer, Dordrecht.

Kim, B.-C. 2006. Development of a broadband selfrecording hydrophone. Ocean \& Polar Res., 28, 145151.

Knudsen, V.O., R.S. Alford, and J.W. Emling. 1948. Underwater ambient noise. J. Mar. Res., 7, 410-429.

Lemon, D.D., D.M. Farmer, and D.R. Watts. 1984. Acoustic measurements of wind speed and precipitation over a 
continental shelf. J. Geophys. Res., 89, 3462-3472.

MacDonald, M.A., J.A. Hildebrand, and S.M. Wiggins. 2006. Increases in deep ocean ambient noise in the Northeast west of San Nicolas Island, California. $J$. Acoust. Soc. Am., 120, 711-718.

Moored Autonomous Hydrophones. <http://www.pmel.noaa. gov/vents/acoustics/haru_system.html $>$.

National Research Council. 2003. Ocean Noise and Marine Mammals. National Academy Press, Washington, DC.
Nystuen, J.A. 1986. Rainfall measurements using underwater ambient noise. J. Acoust. Soc. Am., 79, 972-982.

Urick, R.J. 1983. Principles of Underwater Sound. Peninsula Publishing, Los Altos.

Wenz, G.M. 1962. Acoustic ambient noise in the ocean: Spectra and sources. J. Acoust. Soc. Am., 34, 1936-1956.

Received Nov. 7, 2007

Accepted Dec. 11, 2007 